\title{
O PROCESSO DE APRENDIZAGEM DA LÍNGUA ESCRITA: EMÍLIA FERREIRO E ANA TEBEROSKUY
}

RESUMO - Nos últimos trinta anos a psicolinguística Emília Ferreiro vem se destacando como grande influência na educação brasileira. Em meados de 1980 com a publicação de seus livros causou um grande impacto sobre a concepção existente na época sobre a alfabetização. Emilia diz que "a criança constrói seu próprio conhecimento" (Ferrari, 2008) e é daí que surge a palavra "construtivismo". Isso implica transferir o foco da escola com a alfabetização, para o sujeito que aprende, isto é, o aluno. Através de quatro fases de aprendizado, a autora descreve o processo de evolução da criança através da escrita. Dentro de nossa perspectiva, esse trabalho tem por objetivo versar sobre as duas primeiras fases que dizem respeito ao estágio denominado présilábico e o silábico, em que a criança tem suas primeiras noções no mundo da escrita, motivada pela percepção de que as palavras são um meio de se expressar o que se diz. Desse modo, a partir da pesquisa bibliográfica, buscouse nesse "mundo de descobertas", na qual a criança começa a perceber a relação existente entre a escrita e tudo o que se fala e iniciando pelas garatujas, vai se estendendo em seu desenvolvimento com as palavras, aperfeiçoando cada vez mais sua nova maneira de se comunicar.

PALAVRAS-CHAVE: Alfabetização. Escrita. Aprendizado

\section{INTRODUÇÃO}

Emilia Beatriz Ferreiro Schavi nasceu em Buenos Aires na Argentina no ano de 1936 é psicóloga e pedagoga, estudou na Universidade de Genebra, foi doutoranda de Jean Piaget, continuou com a teoria de Jean Piaget tendo sua teoria baseada no desenvolvimento da criança. Teve grande influência na educação brasileira nos últimos anos. Emilia teve vários livros lançados e um 
deles em meados do ano 1980, com grande impacto na educação brasileira seu livro tinha um olhar para o processo de alfabetização.

Ana Leonor Teberosky Coranado nasceu na Argentina em 1937, fez doutorado em psicologia com especialização em psicologia genética e sua tese também foi dirigida por Jean Piaget. Tornou-se doutora em psicologia e docente do departamento de psicologia evolutiva e da educação na Universidade de Barcelona.

As autoras nos trazem estudos, que nos mostram o quanto as crianças podem evoluir na leitura e escrita. E que os professores precisam compreender o ritmo de cada aluno e quando se deve fazer intervenção necessária para ajudar seu aluno, criando assim, meios para que a criança aprenda e desenvolve suas habilidades, possibilitando sua aprendizagem no mundo da escrita e da leitura. Acreditavam que as crianças buscavam a aprendizagem na medida em que evoluíam aprendendo, assim, ler e escrever passa por vários níveis.

Emilia Ferreiro e Ana Teberosky definem na psicogênese da língua escrita quatro níveis em que a criança poderá passar, a saber:

- $1^{\circ}$ nível: Pré-silábica;

- $2^{\circ}$ nível: Silábico;

- $3^{\circ}$ nível: Silábica-alfabética;

- $4^{\circ}$ nível: Alfabética.

Segundo Emilia Ferreiro e Ana Teberosky, as crianças elaboram conhecimento sobre a leitura e escrita, passando por diferentes hipóteses espontâneas e provisórias - até se apropriar de toda a complexidade da língua escrita (apud MICHELLE, 2010, p. 2).

\section{METODOLOGIA}

Para a realização desse estudo, a abordagem metodológica utilizada foi a pesquisa bibliográfica, buscando-se informações pertinentes sobre a concepção de leitura e escrita a partir de Emilia Ferreiro e Ana Teberosky, com a pesquisa foi possível colher dados em vídeos e artigos científicos 
disponibilizados na rede, atribuindo maior embasamento ao objetivo proposto neste trabalho.

\section{NA PSICOGÊNESE DA LÍNGUA ESCRITA: NÍVEIS PRÉ-SILÁBICO E SILÁBICO}

Desde muito cedo, a criança reconhece e compreende a existência da escrita, passando a imitar os adultos na tentativa de se comunicar através da escrita também.

Segundo Michele (2014), a interpretação que a criança faz da escrita está muito além da simples associação de fonemas e grafemas, assim, a autora destaca que:

Antes da entrada do construtivismo no cenário educacional brasileiro, as práticas alfabetizadoras eram (e ainda são) baseadas na memorização das correspondências entre sons e letras, reduzindo a aprendizagem da língua a um conjunto de sons a serem representados por letras. A alfabetização era entendida como mera sistematização do ' $B+A=B A$ ', isto é, como aquisição de um código fundado na relação entre fonemas e grafemas."

De acordo com este artigo, publicado por Michelle (2010), a Psicogênese da língua escrita, o que existe entre a criança e a escrita, não é um mero ato de memorização, mas sim, muito, além disso, o que ocorre é um fenômeno de transformação social, derivado do conhecimento que a criança tem de si mesma e do mundo que a rodeia, fazendo com que através da escrita, ainda que sem dominá-la especificamente, se aventure na tentativa de se expressar através desse método de comunicação.

No entanto, não devemos considerar a teoria do construtivismo, que tem a psicogênese como objeto de estudo, uma metodologia de ensino "[...] já que esta teoria psicológica da aprendizagem volta-se para a compreensão de como o sujeito aprende e não para a questão de como o/a professor/a deve 
ensinar" (MICHELLE, 2010). Sendo assim, quando falamos da psicogênese, não discorremos sobre como se ensina e sim de como se aprende.

No processo de aprendizado da língua escrita, a criança passa por quatro fases de aprendizado, que são o pré-silálico; silábico; silábico-alfabético e alfabético. Neste artigo discorreremos sobre as duas primeiras fases deste processo de aprendizado, em virtude de esses dois primeiros níveis terem impressionado muito alguns dos integrantes de nosso grupo, pelo fato de estarem presentes em seu de dia-a-dia, pois os mesmos trabalham na educação infantil do Município de Rio Branco-MT, vivenciando essas duas fases do aprendizado infantil em sua rotina de trabalho.

\subsection{PRÉ-SILÁBICO}

Pré-silábico é o primeiro nível no processo de aprendizado da língua escrita infantil, quando a criança passa a ter a noção de que a escrita representa aquilo que é falado. O infante observa os adultos à sua volta e começa a perceber a relação existente entre aquilo que eles escrevem e aquilo que eles falam, iniciando a partir desse instante um processo quase que inevitável de reprodução das atitudes dos maiores à sua volta, fazendo rabiscos e desenhos (conforme a figura 1 e 2 ), de tudo que para elas representa aquilo que é dito, pois "o/a alfabetizando/a não compreende a natureza do nosso sistema alfabético, no qual a grafia representa sons, e não ideias [...]" ((MICHELLE, 2010).

Figura 1:

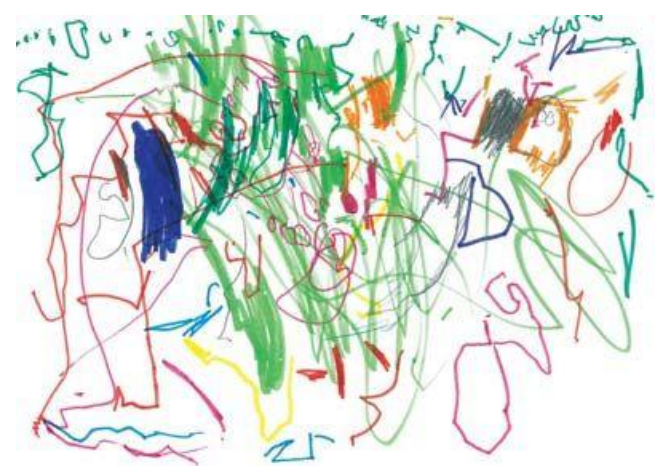

http://portaldoprofessor.mec.gov.br (Criança desenhando um cavalo), 2018. 
Figura 2:

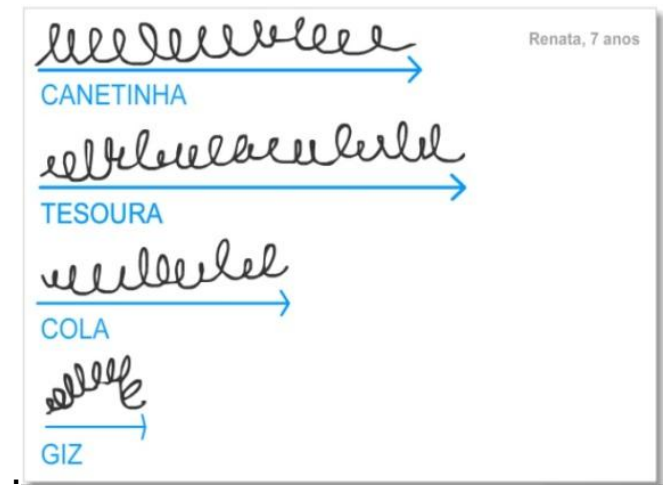

Fonte: http://slideshare.net/RayanePaula1/hiptese, 2018.

Com a sequência de construção das garatujas pelas crianças, passam a ganhar forma, pois a criança começa a identificar algumas letras (conforme figura 3), especialmente àquelas que estão relacionadas ao seu nome. E utilizando-se dessas letras, começa a partir de então, utiliza-las para representar outras palavras diferentes.

Figura 3:

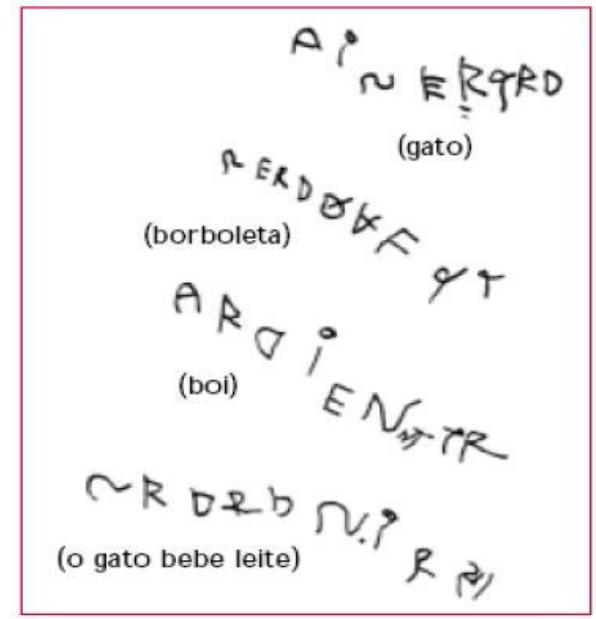

Fonte: http://cantinhocriativodalu.blogspot.com.br, 2018.

Geralmente o que acontece é apenas a inversão das letras que formam seu nome e ainda que pela lógica, não seja nem de longe a descrição correta das palavras objetivadas, para a criança, ali está transcrita sua real compreensão da palavra imaginada. 
Outro fator interessante e de muita importância relacionado a este nível de aprendizado diz respeito à característica que a criança adquire com relação às palavras, no sentido de associá-las ao tamanho do objeto descrito, por exemplo, se a criança for escrever as palavras "vaca" e "lagartixa", dentro de sua perspectiva a palavra maior seria VACA e a menor seria LAGARTIXA, pois há associação ao tamanho do animal ao tamanho do seu nome.

Nessa fase também, a criança representa a escrita através de duas hipóteses: Icônica e não Icônica. A icônica funciona como expressão de seu pensamento através de desenhos, pois a criança ainda não tem noção da escrita propriamente dita, para a criança escrever é a mesma coisa que desenhar. A não icônica, diferentemente da outra hipótese, funciona como expressão do pensamento através de rabiscos, isso vai além dos desenhos, nesse âmbito a criança inicia o conceito de escrita, mas não conhece a letra do alfabeto e seu fonema.

\subsection{SILÁBICA}

$\mathrm{Na}$ escrita silábica, a criança inicia o processo de associação entre fonemas e grafemas, começando a relacionar o som das letras a palavras que fazem parte de seu vocabulário, sendo, no entanto, ainda bem rústicas e às vezes distantes do contexto dito explicitamente correto. Porém, na perspectiva da criança isso representa uma grande evolução quando comparado com seu estágio anterior no momento em que se notava a presença das garatujas, por exemplo, (conforme figura 4).

[...] a criança supõe que a escrita representa a fala. É a fase que se inicia o processo de fonetização; nesta fase, ela tenta fonetizar a escrita e dar valor sonoro às letras. Cada sílaba é representada por uma letra com ou sem conotação sonora. Em frases pode escrever uma letra para cada palavra. 
Figura 4:

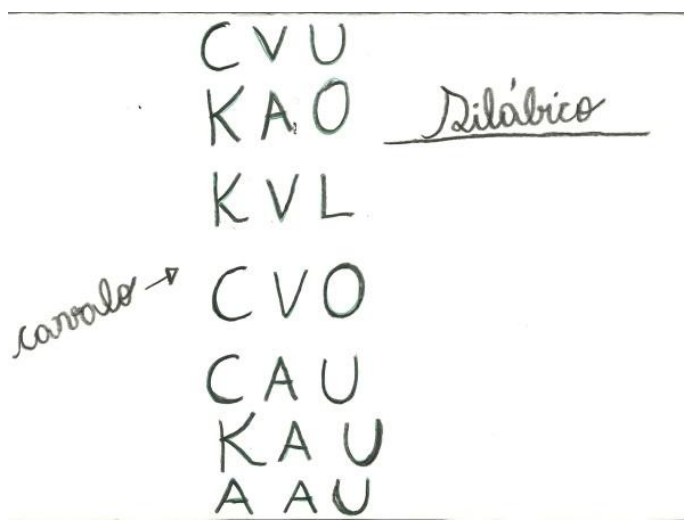

Fonte: http://ensinar-aprender.com.br, 2018.

Conforme vimos na imagem acima, no nível silábico, a criança já começa a perceber a relação existente entre as palavras e os fonemas oriundos de cada uma delas. É um momento de descobertas, portanto a variação de sua compreensão de uma única palavra pode ser bem diversificada, como no exemplo ilustrado acima, onde se utilizam várias junções de letras, diferentes entre si, para significar uma única palavra; no caso, a imagem retratou a palavra "cavalo".

A partir de então, a criança passa a se desenvolver cada vez mais, rompendo suas próprias limitações, adentrando cada vez mais no mundo do conhecimento da escrita e da leitura, alcançando sempre novos horizontes, no conhecimento que ela tem do mundo à sua volta e de si mesma.

Entendemos que esse desenvolvimento varia muito de educando para educando, fazendo com que crianças da mesma idade possam atingir níveis de aprendizado diferentes, ainda que tenham a mesma idade e estudam na mesma escola, com o mesmo professor. Cada criança tem seu tempo para aprender e evoluir, sendo que esse tempo individual de cada uma deve ser compreendido e estimulado, mas acima de tudo, respeitado.

\section{CONSIDERAÇÕES FINAIS}


Diante de tudo o que foi exposto, constata-se a existência de um incrível mundo de aventura pelo qual a criança passa até compreender de uma maneira mais concisa em relação ao processo da escrita. Percebe-se o respeito que deve existir pelo conhecimento pré-adquirido da criança e que não importa seu grau de desenvolvimento no sistema de escrita, a criança deve ser compreendida e levada à ampliação de suas habilidades.

Essa reflexão, foi alicerçada não apenas através de material bibliográfico, mas também através de alguns vídeos sobre o assunto, onde de constatou visivelmente os processos de evolução pelo qual a criança passa no aprendizado da escrita, e ao mesmo tempo, o que a escrita representa para a criança em seus diferentes níveis de conhecimento, tornando com toda certeza o estudo muito mais atrativo e agradável, pois comprovou-se a relação existente entre tudo o que foi lido durante a pesquisa e as atitudes das crianças no tocante ao ato de escrever de maneira significativa.

Em suma, conclui-se que não importa o nível de aprendizado da criança, como futuros educadores precisamos sempre compreender sua maneira de pensar e agir, entendendo que o mais importante na educação, não está relacionado a como se ensina e sim, como a criança aprende.

\section{REFERÊNCIAS:}

FERRARI, Marcio. Publicado em Especial grandes Pensadores, outubro 2008. Disponível em: http://educarparacrescer.abril.com.br/aprendizagem. Acesso em: 20/07/2018.

MICHELLE, Ana. Secretaria Municipal de Educação e Cultura - SMEC, Coordenação de ensino e apoio pedagógico - CENAP. Espaço Pedagógico virtual: Teias de conhecimento e saberes, 2010. Disponível em: http://psicopedagogiaeducacao.blogspot.com.br > Acesso em: 20/07/2018. http://portaldoprofessor.mec.gov.br. Acesso em 20/07/2018. http://slideshare.net/RayanePaula1/hiptese. Acesso em 20/07/2018. http://cantinhocriativodalu.blogspot.com.br. Acesso em 20/07/2018. http://ensinar-aprender.com.br. Acesso em 20/07/2018. https://www.youtube.com/watch?v=B0cyJgzkB6w> Acesso em: 20/07/2018. 
https://www.youtube.com/watch?v=NCo5ybibn5Q > Acesso em: 20/07/2018.

https://www.youtube.com/watch?v=N0jC-gZ9QUY> Acesso em: 20/07/2018. 